\title{
Comparing flow-through and static ice cave models for Shoshone Ice Cave
}

\author{
Kaj E. Williams ${ }^{1,2^{*}}$ and Christopher P. McKay ${ }^{1}$ \\ ${ }^{1}$ NASA Ames Research Center, Division of Space Sciences and Astrobiology, Mail Stop 245-3, Moffett Field, CA 94035 \\ ${ }^{2}$ Montana State University, Department of Earth Sciences, Bozeman, MT 59717
}

\begin{abstract}
In this paper we suggest a new ice cave type: the "flow-through" ice cave. In a flow-through ice cave external winds blow into the cave and wet cave walls chill the incoming air to the wetbulb temperature, thereby achieving extra cooling of the cave air. We have investigated an ice cave in Idaho, located in a lava tube that is reported to have airflow through porous wet endwalls and could therefore be a flow-through cave. We have instrumented the site and collected data for one year. In order to determine the actual ice cave type present at Shoshone, we have constructed numerical models for static and flow-through caves (dynamic is not relevant here). The models are driven with exterior measurements of air temperature, relative humidity and wind speed. The model output is interior air temperature and relative humidity. We then compare the output of both models to the measured interior air temperatures and relative humidity. While both the flow-through and static cave models are capable of preserving ice year-round (a net zero or positive ice mass balance), both models show very different cave air temperature and relative humidity output. We find the empirical data support a hybrid model of the static and flow-through models: permitting a static ice cave to have incoming air chilled to the wet-bulb temperature fits the data best for the Shoshone ice cave.
\end{abstract}

Received 17 February 2014; Revised 21 October 2014; Accepted 8 January 2015

Keywords: $\quad$ ice cave; latent heat; airflow; Shoshone Ice Cave; USA

Citation: Williams K.E. and McKay C.P., 2015. Comparing flow-through and static ice cave models for Shoshone Ice Cave. International Journal of Speleology, 44 (2), 115-123. Tampa, FL (USA) ISSN 0392-6672 http://dx.doi.org/10.5038/1827-806X.44.2.2

\section{INTRODUCTION}

Ice caves are broadly defined as rock-hosted caves that contain year-round ice deposits for two or more years. Ice caves are relatively common and have been found in surprisingly warm and arid climates, including New Mexico, California and southern Idaho (USA). The source of the cave ice can be atmospherically deposited frost, frozen ponded rainwater, snowmelt that subsequently refreezes within the cave, windblown snow or combinations of these sources.

Ice caves have been studied for centuries (e.g., Browne, 1865; Balch, 1900). Micrometeorological studies of ice caves are relatively plentiful in the literature and modeling studies often include both theoretical and data-driven approaches (c.f. Ohata etal., 1994; Obleitner \& Spötl, 2011; Luetscher et al., 2008). Airflow in caves is an important micrometeorological variable, and airflow may be caused by a variety of factors (Badino, 2010) which are discussed below. Accordingly ice caves have been classified broadly in terms of two ventilation types: static vs. dynamic (c.f. Luetscher \& Jeannin, 2004). Static caves function as a cold trap, where seasonal thermal asymmetries drive cold external air into the cave. Dynamic caves are multiple-entrance caves where thermal gradients exist between one or more entrances and the interior cave walls (creating a chimney effect). Dynamic caves usually have entrances at different elevations.

The airflow for static ice caves discussed in the literature is based on a seasonally asymmetric air exchange mechanism, and hence on ice cave geometries idealized as a pit or a subterranean room with no air drainage possibilities. For such a configuration (Fig. 1A), relatively cold air settles by gravity into the cave during the winter months, whereas in the warm summer months the outside ambient air is too warm to sink into the cave. Hence, there is an active circulation between the exterior and the cave during the cold winter but the air circulation usually ceases during the summer.

Dynamic ice caves are defined as caves that have multiple entrances at different heights, which leads to airflow that is governed by temperature gradients within the cave itself as well as between the cave interior and exterior (Fig. 1B). Cave interior wall 


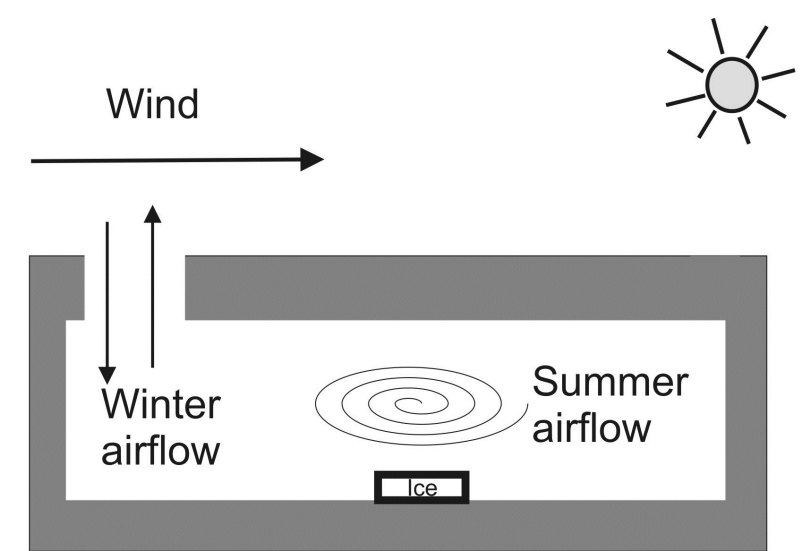

A.

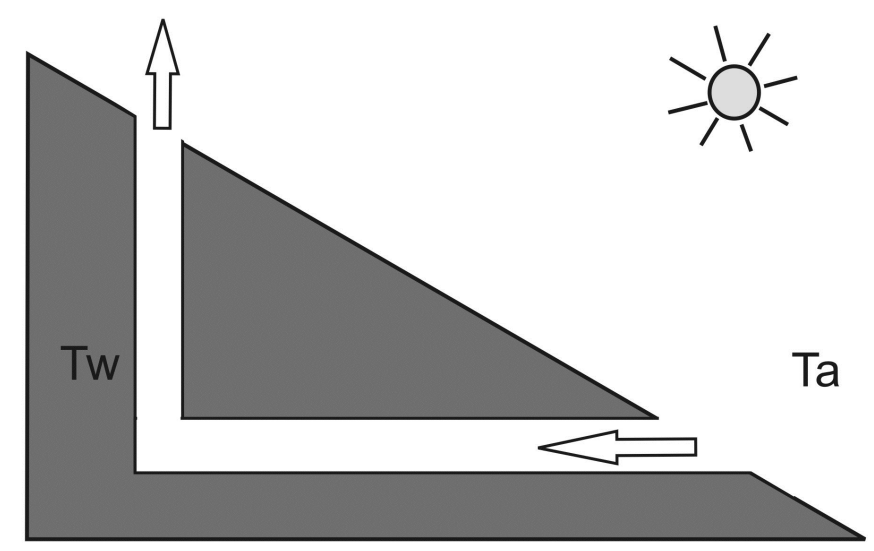

B.

Fig. 1. General airflow patterns and configuration of the static $(A)$ and dynamic (B) cave types. In (B) the winter airflow is shown, where the interior wall temperature Tw is warmer than Ta, the air temperature at the lower entrance. In the summer, the airflow of $(B)$ is reversed as cool air descends the chimney and flows out of the bottom entrance.

temperatures are usually much less dynamic than exterior air temperatures, leading some researchers to simply state that air temperatures within inner sections of caves are nearly constant (Wigley \& Brown, 1976; also discussed in Luetscher \& Jeannin, 2004), though work by Pflitsch \& Piasecki (2003) has provided a more nuanced view. Accordingly, in the winter the temperature at the lower entrance is colder than the cave interior. Cave walls warm the interior air, which rises and escapes from the upper cave entrance resulting in cold air being sucked into the lower entrance of the cave. In the summer there is a reversal of the winter pattern, where the cooler cave interior air drains out of the lower entrance, resulting in relatively warm air flowing into the upper entrance. Thus in both winter and summer the lower entrance of the dynamic cave is cooler than the upper entrance (assuming a significant elevation difference between upper and lower entrances). If the difference is extreme enough ice can persist near the lower entrance. A combination of the static and dynamic cave types, termed "statodynamic" caves, is possible as well, and in fact may be the most common type (Luetscher \& Jeannin, 2004).
In addition to classifying ice caves according to ventilation characteristics, Luetscher \& Jeannin (2004) and other researchers have extended the above classification by considering broad origin types for the ice: endogenous vs. exogenous. Endogenous ice includes congelation ice, and exogenous ice is used to refer to external ice and snow transported into the cave (e.g. wind-blown snow). In this study we will consider primarily congelation ice. None of the above types of ice caves preclude, for a given year, mass loss of at least some of the ice within the cave (i.e. a negative ice mass balance for a given year). Indeed, sublimation and melting are the two mechanisms for loss, and research indicates that there can be pronounced interannual variability of the ice mass balance within ice caves (Ohata et al., 1994; Schöner et al., 2011). At certain times of the year, often in late spring and summer, there can be quantities of water on top of the ice (Balch, 1900; Perşoiu et al., 2011 b), which will subsequently refreeze later in the year. The source of a liquid water layer on top of the ice can be percolating water from rain or snowmelt (Perşoiu et al., 2011b; Schöner et al., 2011) or it could be the result of melting of the ice surface within the cave itself (Ohata et al., 1994).

Local air pressure differences between the cave interior and exterior can also cause airflow (Badino, 2010). Such differences can result in a small but noticeable airflow, including associated reverse flows as pressure gradients change; caves where such flow occurs are sometimes referred to as "breathing caves" (Wigley, 1967). Breathing caves can exhibit diurnal or seasonal flow patterns. In addition Perşoiu et al. (2011a) have recently shown that differences in air temperature within a particular ice cave can influence ice mass balance, as well as moisture circulation. Of course, a given cave airflow may be the result of multiple mechanisms acting simultaneously.

The focus of the present study is the Shoshone Ice Cave, which is located in a horizontal lava tube north of Shoshone, ID. The cave was originally a natural ice cave with rock falls on both ends but with one end more completely sealed by a rock fall and massive ice deposits (Harrington, 1934). Shoshone Ice Cave is no longer "natural", however it was a natural ice cave until $\sim 100$ years ago, when the entrance was dynamited to allow easier access (Harrington, 1934). While the cave does vary slightly in both diameter and orientation, the centerline of the cave is estimated to follow an orientation of $\sim 315^{\circ}$. The diameter of the cave is estimated to be $\sim 20 \mathrm{~m}$ and the length several hundred meters.

The present-day owners of the cave have reported to the authors that wind is frequently felt within the cave. The authors also observed the presence of wet and porous walls at both ends of the cave, including the end where the staircase and door are located. In particular, the doorway is set within a large pile of cobbles where copious amounts of water were observed dripping on the inside of the cave wall; several meters further into the cave the walls are coated with fine frost crystals. Those observations motivate this study, in that they suggest that any winds forced through the moist cobbles and into the 
cave is most likely subjected to strong evaporative cooling at the entrance.

As a working hypothesis, then, we suggest an ice cave type where evaporative cooling plays a significant role in the preservation of ice: the flow-through ice cave. An idealization of such a cave would be a lava tube with both ends filled with loose piles of cobbles, such as a rock fall. The pile of moist cobbles presumably cools the air more efficiently (via turbulent mixing within the pile) than simple airflow past a moist wall. Depending on the prevailing wind direction, the orientation of such caves may permit the interior to be well-ventilated, or it might permit ventilation to occur only under specific wind-directions (or other conditions, such as snow/ice accumulating preferentially in one or more cave entrances resulting in seasonal ventilation differences). For the purposes of this study, we will assume that the ends of the lava tube are permeable to both wind and water, and therefore that our idealized flow-through cave has persistent ventilation (always permeable to wind), shown in Fig. 2.

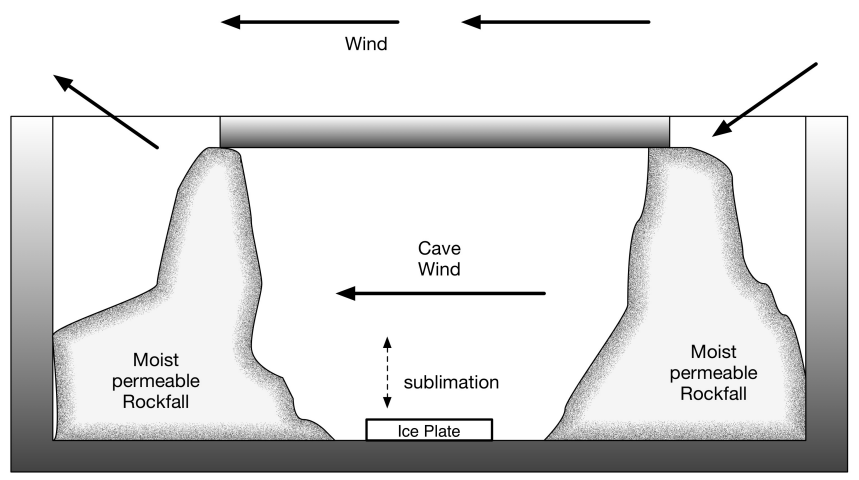

Fig. 2. An alternate cave model configuration: the "flow-through" ice cave. The intact portion of the lava tube is bounded by two collapsed areas of the ceiling. The two chimneys are relatively wide in order for winds to blow into the moist rock fall relatively unimpeded. Diagram not to scale.

In order to determine which of the above cave types is (are) applicable to Shoshone, we have instrumented the cave interior and exterior in order to understand the temperature and $\mathrm{RH}$ regimes more clearly. Qualitatively, if the flow-through cave type is appropriate for Shoshone, then the interior air temperatures should vary on similar timescales as the prevailing exterior temperatures, since exterior cave air (albeit cooled by the moist cave ends) is frequently flushed through the cave. On the other hand, if the static cave configuration is appropriate, we should see significant interior air temperature variation only during the months when airflow is achieved (winter).

\section{FIELD METHODS}

We have instrumented both the interior and exterior of the Shoshone Ice Cave in order to collect air temperature and relative humidity data. The exterior temperature and relative humidity sensors (Hobo Pro v2 with a standard radiation shield) were placed at approximately $1.5 \mathrm{~m}$ height, in an open area approximately 200m ESE of the cave entrance attached to an existing utility pole. The cave interior air temperature and relative humidity sensors (Hobo Pro v2) were placed approximately $2 / 3$ of the distance down the cave centerline, $\sim 3 \mathrm{~m}$ from the wall, and $\sim 1 \mathrm{~m}$ above the summer ice/water surface (as of late June 2012). We affixed the cave interior sensors below the catwalk because, according to the cave owners, the water level on top of the floor ice can vary throughout the year; the catwalk was deemed less likely to be submerged than an arbitrary datum selected near the existing ice surface level.

We were unable to measure the annual ice mass balance on the cave floor, but it suffices in this study to note that Shoshone Ice Cave does indeed contain year-round ice. Ideally, we would also like to have measurements of cave interior wind speed, but unfortunately the cave interior wind speeds were not able to be measured directly. The interior cave air speed is varied, however, as a parameter in the numerical models (explained later in the modeling section).

\section{DATA DESCRIPTION AND RESULTS}

The data measured at Shoshone Ice Cave are summarized in Fig. 3. As expected, the exterior cave air temperature and relative humidity (Fig. 3B) follow a slow seasonal variation, beginning with warm dry air in the summer and followed by cold humid air in the winter months. As shown in Table 1, the air temperatures had a mean of $-0.7^{\circ} \mathrm{C}$, median of $0.0^{\circ} \mathrm{C}$, max. of $0.9^{\circ} \mathrm{C}$ and min. of $-7.4^{\circ} \mathrm{C}$. The interior air measurements, however, do not follow the exterior data in an obvious way. As can be seen in Fig. 3A, the relative humidity stays mostly constant throughout the year, with the exception of the midwinter months. During the midwinter months, both interior relative humidity and temperature dip noticeably.

The wind data was sourced from a U.S. Forest Service and Bureau of Land Management Remotely Automated Weather Station (RAWS) meteorological station in Rock Lake, ID, which is located $\sim 31.1 \mathrm{~km}$ ESE of the Shoshone Ice Cave. The ice cave is located on a topographic rise, at an elevation of 1411 MASL, whereas Rock Lake, ID is at 1298 MASL.

\section{NUMERICAL MODELS}

Ideally, the temperature and relative humidity variations found in the data should be consistent with either static or a flow-through cave types, or perhaps some combination (note that we have eliminated the dynamic cave as a possible type, due to Shoshone Ice Cave having entrances at approximately the same elevation as is typical for a lava tube.) In order to determine the type most applicable to Shoshone Ice Cave, we have constructed two numerical models. We have then applied the two numerical ice cave models to the Shoshone location: a flow-through model (Fig. 2) and a static model (similar to Fig. 1A). The flow-through model is driven by exterior wind, air temperature and relative humidity measurements. The static model is driven by exterior air temperature and relative humidity measurements. Both models have two dependent variables: interior cave air temperature and relative humidity. 


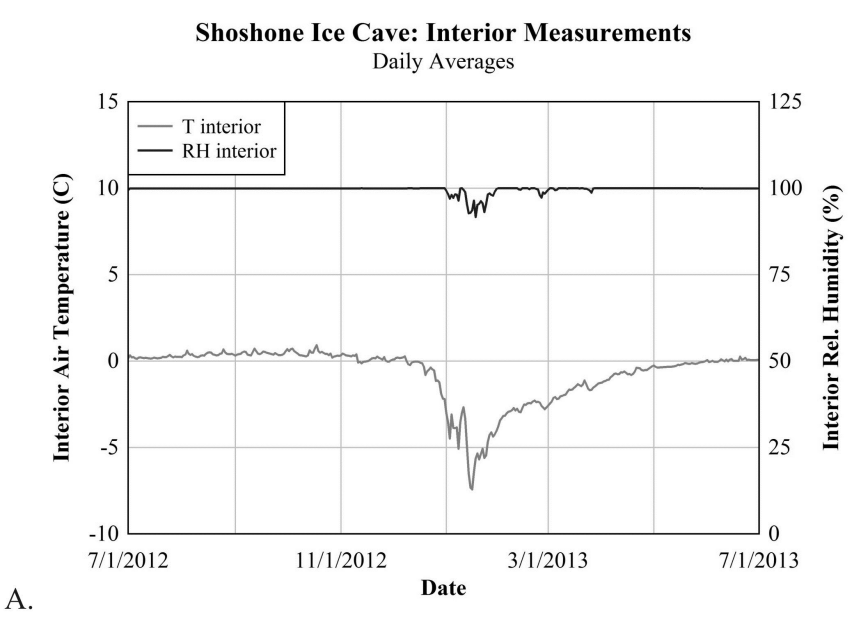

A.



B.

Fig. 3. Daily average interior (A) and exterior (B) cave air temperature and relative humidity measurements.

We first discuss the construction of each model, and later discuss the model output and compare it with the data in order to determine the model fidelity.

\section{Flow-through model}

The Flow-through cave model (Fig. 2) is essentially a lava tube with moist rock fall blocking both ends, where a chamber with an ice plate is located in between the ends. The cave ceiling is assumed to be at sufficient depth to justify ignoring the heat conduction from the soil surface (cave ceiling depth is greater than the annual thermal skin depth). The rock fall is assumed to be permeable to wind and consistently wet from the incoming flow of ground water. The temperature of the moist permeable rock fall at the incoming end is assumed to be at the wetbulb temperature of the outside air. Our reasoning is

Table 1. Statistical properties of the measured data for Shoshone Ice Cave.

\begin{tabular}{|l|c|c|c|c|c|}
\cline { 2 - 6 } \multicolumn{1}{c|}{} & mean & median & min & max & $\begin{array}{c}\text { Std. } \\
\text { dev. }\end{array}$ \\
\hline $\begin{array}{l}\text { Data } \\
\text { interior } \mathrm{T}\end{array}$ & $-0.7^{\circ} \mathrm{C}$ & $0.0^{\circ} \mathrm{C}$ & $-7.4^{\circ} \mathrm{C}$ & $0.9^{\circ} \mathrm{C}$ & $1.6^{\circ} \mathrm{C}$ \\
\hline $\begin{array}{l}\text { Data } \\
\text { interior } \mathrm{RH}\end{array}$ & $99.7 \%$ & 99.9 & $91.7 \%$ & $100.0 \%$ & $1.1 \%$ \\
\hline $\begin{array}{l}\text { Data } \\
\text { exterior T }\end{array}$ & 9.2 & 9.4 & -17.0 & 29.3 & 11.2 \\
\hline $\begin{array}{l}\text { Data } \\
\text { exterior } \mathrm{RH}\end{array}$ & 55.1 & 53.7 & 13.6 & 100.0 & 25.1 \\
\hline
\end{tabular}

that the end material is constantly exposed to external winds, but is also constantly being moistened by groundwater percolating from above (Fig. 2). In our estimation the temperature of the end material is not important because the cooling of the incoming air is dominated by latent heat exchange.

The incoming cave air passes through the permeable material at the end of the cave, and hence is chilled to the wet-bulb temperature of the external air. In this flow-through cave configuration we assume that the cave air does not linger (typical interior air speeds are $1-10 \mathrm{~m} / \mathrm{s}$, depending on model configuration), and therefore the interior cave walls and ice plate (on floor) do not heavily influence the cave air temperature and $\mathrm{RH}$.

Our model of the ice in this case is a 1-D heat and mass transfer model of an ice plate, $1 \mathrm{~m}^{2}$ in extent, located on the cave floor. The ice plate is always shaded from the sun. Similar to the snowpack model in Williams et al. (2008), the model employs a controlvolume approach, where for a given volume we can equate the time rate of change of a conserved quantity (mass and energy) with a surface integral of a flux averaged over a specified time interval. The energy balance is computed at the ice surface as well as within the material column.

Given the usual assumption of homogeneity of the conserved quantity $\Phi$ over the designated control volume, we may represent the mass or energy balance within a layer $\mathrm{k}$ of thickness $\Delta z$ :

$$
\frac{\partial}{\partial t} \Phi=-\sum \overline{\left(J^{k+1 / 2}-J^{k-1 / 2}\right)}+\overline{\Psi \Delta z}
$$

Here $\Phi$ has been normalized per unit area, $\Psi$ is a source term for the volume element, and $\mathrm{J}$ is a flux density. Equation (1) is for a control volume and the node $\mathrm{k}$ corresponds to the center of the $\mathrm{k}$-th volume element (in this study a layer). The $\mathrm{k}-1 / 2$, $\mathrm{k}+1 / 2$ indices correspond to the upper and lower faces of the volume element (layer). In the case of our 1-D ice model for the cave floor, the conserved quantity is the ice/water layer energy U normalized per unit area where $U=\rho C \rho T \Delta z$. Here the material bulk density is $\rho$, the specific heat capacity $\mathrm{Cp}$ and the temperature $\mathrm{T}$ for a volume of dimensions $1 \mathrm{~m}^{2}$ by $\Delta z$. The energy $\mathrm{U}$ of the layer is then evolved in time by solving:

$$
\frac{\partial U}{\partial}=-\overline{\left[\left(\left.k(T) \frac{\partial T}{\partial z}\right|_{j+1 / 2}-\left.k(T) \frac{\partial T}{\partial z}\right|_{j-1 / 2}\right)+\left(F n e t^{j+1 / 2}-F n e t^{j-1 / 2}\right)\right]}+\overline{\zeta \Lambda z}
$$

Here the overbar indicates that the fluxes are averaged over an interval at least as long as the designated integration timestep interval, and since in our case $\mathrm{U}$ is normalized per unit area, it has units of $\mathrm{J} / \mathrm{m}^{2}$, giving the left-hand side of Equation (2) units of $\mathrm{W} / \mathrm{m}^{2}$. The $(\zeta \Delta z)$ term on the right-hand side of Equation (2) is the average energy source/sink rate contributed by the arrival/departure of mass in the layer for the current timestep, and has units of $\mathrm{W} / \mathrm{m}^{2}$. In this particular model, mass loss or gain only occurs in the topmost layer, whereas lower layers are not permitted to gain 
or lose mass and hence are uniform in thickness. Fnet is the net energy flux at the control volume boundary due to either latent or sensible heat. Fnet is nonzero only for the surface (topmost) layer of ice.

The topmost ice-layer sensible and latent heat turbulent fluxes are given by the following aerodynamic expressions as used in Paterson (1994):

$$
\begin{gathered}
H=\rho C p A u(T-T s) \\
E=0.622 L_{v} A u\left(e-e_{s}\right) \rho_{0} / P_{0}
\end{gathered}
$$

Here $\rho$ is the atmospheric density, $\mathrm{P}$ is atmospheric pressure and the 0 subscript indicates reference values. $\mathrm{L}_{\mathrm{v}}$ is the latent heat of vaporization (if melting ice) or Ls for latent heat of sublimation if ice is sublimating, e and $\mathrm{e}_{\mathrm{s}}$ are the vapor pressure and saturation vapor pressure of water vapor, $\mathrm{u}$ is wind speed (explained below), $\mathrm{Cp}$ is specific heat capacity, $\mathrm{T}$ and $\mathrm{Ts}$ are the temperatures of the atmosphere and surface respectively. A is the (unitless) heat transfer coefficient over ice, where $\mathrm{A}=0.002$ as given in Paterson (1994). When the situation permitted, Equations (4-5) were used to compute condensation. Hence the model included both evaporation/sublimation (mass loss) from the ice surface as well as condensation (mass gain).

The ice plate on the cave floor is unaffected by the sensible heat effects of from the rock walls and ceilings since we assumed they were (with the exception of the ice plate) all the same temperature.

The flow-through ice cave model is driven with hourly temperature and relative humidity data from the external sensors. Hourly averaged variables for ambient air Temperature, Humidity, and wind speed and wind direction were used (hence the mass balance within the cave was computed at every hour throughout the modeled year). Wind direction was used to scale the cave air wind speed by the cosine of the angle between the longitudinal cave axis orientation studied and the wind direction. Using data from a nearby RAWS station, rather than a collocated one, may have consequences with the wind frequency and magnitude. We feel, however, that in general winds will be similar enough between the two locations to capture the annual trends at the ice cave.

At the beginning of every month, the mean monthly (computed from 1910-2010 RAWS records for Rock Lake, ID) precipitation amount was assumed to have percolated into the cave and onto the ice surface. Hence on the first day of every month, a small amount of water was deposited (at a temperature of $+1^{\circ} \mathrm{C}$ ) onto the surface of the cave ice. While the conductive heat transfer between the water later and the ice beneath is included in the model, in practice the temperature of the small layer of water does not have much influence on the energy balance of the ice column beneath, since it contributes only a small amount of energy to the column (E.g. the internal energy of the topmost liquid water layer will change by $<<1 \%$ as a result of $1^{\circ} \mathrm{C}$ temperature change).

The ice thickness was initially $1 \mathrm{~m}$, set over a substrate column consisting of $5 \mathrm{~m}$ of vesicular basalt with water-filled pores. The thermal conductivity of the basalt substrate was taken to be $1,634 \mathrm{~W} / \mathrm{mK}$, which is an average of data given in Robertson \& Peck (1974). The geothermal heat flux, applied to the bottom layer in the material column, is estimated from Wisian et al. (1999) to be $0.120 \mathrm{~W} / \mathrm{m}^{2}$ for the southern Idaho region.

The model used $1 \mathrm{~cm}$ layers for the computational grid. The ice column initially had no water layers present, since the model was started on $6 / 30 / 2012$ (at the end of the month). Note, however, that there was emplaced the requisite amount of water on the ice surface only a few days later on $7 / 1$ in accordance with our liquid water emplacement scheme.

It is expected that the airflow speeds in the cave are less than the exterior (surface) wind speeds. If we restrict our attention to ice caves which have more than one entrance (and in our simplified model, the cave entrances are at the same elevation), it is possible that the interior airflow speeds would be significantly lower than the exterior winds if the entrances are occluded by rock fall. Research by Schöner et al. (2011) of the Eisriesenwelt, an ice cave in the Austrian Alps with two open ends, has shown interior airflow speeds to be significantly less than surface winds (depending on the location in the cave, and the cave geometry). Accordingly in this present modeling study we have varied runs with interior airflow speeds ranging from $100 \%$ of the exterior wind speeds, down to $1 \%$ (explained later). The airflow in the cave interior is assumed to occur at the same time and last for the same duration as the exterior winds.

\section{Static model}

The Static ice cave model (Fig. 4) is slightly more complex than the flow-through model as outlined above. Equations (1-2) are used for the ice column in the floor and a separate set of Equations (1-2) are computed for the wall material column. The additional complexity is due to the static cave model requiring careful attention to the cave air vapor mass and temperatures responding to the presence of cave walls and the ice/water surface. The flow-through model assumed that, once the incoming air was chilled to the wet-bulb temperature by moving through the wet porous cave ends, the air moving through the cave was not subsequently changed by the water/ice on the floor (since the cave air was only peripherally next to those surfaces). Unlike the flow-through model, however, the static cave model assumes that the cave

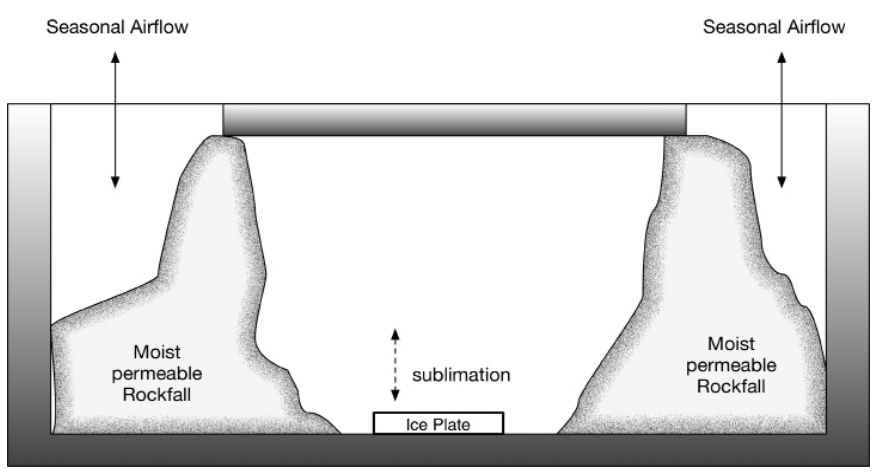

Fig. 4. The static ice cave model. Note that this is similar to Fig. 2 but without constant wind, in which case air can simply move into or out of the cave with through the porous end plugs similar to the air movement through the chimney of a static cave as shown in Fig. 1A. 
air may be quiescent, and hence in direct contact with the water/ice and wall surfaces for extended time periods. The wall and floor temperature is influenced by the cave air temperature and relative humidity, and the wall and floor temperature in turn influences the air temperature. Again, as with the flow-through case, the cave ceiling is assumed to be at sufficient depth to justify ignoring the heat conduction from the soil surface.

External air temperature and humidity data is read every hour. The cave air temperature and humidity are computed throughout the year over 1-30 minute subintervals (depending on numerical stability requirements for energy and mass conservation within the cave). Every hour, however, the external air temperature is compared with the internal air temperature. If the internal temperature is warmer than the exterior air, the cave air is flushed (removed) and the external air is brought into the cave. The new cave air "slug" is then permitted to equilibrate with the cave walls and floor. The result is that the cave air slug gradually changes temperature and relative humidity, and that in turn it slightly alters the temperature of the cave walls.

Sensible and latent heat is transferred between the floor/walls/cave air depending on temperature and mass gradients. Since the cave air (in the static cave case) is generally quiescent it is necessary to compute free convective fluxes. Following Campbell $\&$ Norman (1998), both the sensible and latent heat was computed as a laminar free convective flux. When the surface temperature is warmer than the air temperature, the flux was computed as

$$
H=c_{p} g_{H}\left(T_{s}-T_{a}\right)
$$

where $c_{p}$ is the specific heat capacity of air, $T_{s}$ and $T_{a}$ is the surface and air temperature, respectively. The conductance $g_{H}$ was computed as

$$
g_{H}=0.05\left(\frac{\left(T_{s}-T_{a}\right)}{d}\right)^{1 / 4} \quad\left\{\frac{m o l}{m^{2} s}\right\}
$$

where $d$ is the characteristic dimension, which in this case is half of the cave radius.

When the surface was colder than the overlying air, the sensible heat was scaled by 0.5 as recommended in Campbell \& Norman (1998).

Similarly, the latent heat was computed as

$$
E=g_{v}\left(C_{v s}-C_{v a}\right)
$$

where $\mathrm{C}_{\mathrm{vs}}$ and $\mathrm{C}_{\mathrm{va}}$ are the molar concentrations of water vapor at the ice surface and in the center of the cave air, respectively. Following Campbell \& Norman, the mass conductance $g_{v}$ was computed by scaling the sensible heat conductance by 1.09 .

The flow-through model was run for one calendar year, from $7 / 1 / 2012-6 / 30 / 2013$. The results are shown in Fig. 5. The modeled ice/water mass balance for the given year is shown in Fig. 6. When the interior wind speed is identical to the exterior wind measurements (100\% scaling as depicted in Fig. 6), the flow-through model produced a slightly negative mass balance over the course of the year studied. Interior cave wind set at $10 \%$ or $1 \%$ of the exterior wind yields a positive annual mass balance (10-15\%). When the cave airflow within the flow-through model is reduced to $61 \%$ of the exterior air speed, a positive annual ice mass balance is achieved. Unfortunately no mass balance observations of the ice on the cave floor are available to compare with. Our observation on June 30, 2012 confirmed that large amounts of ice were present on the cave floor, together with a shallow (1-2 cm) layer of water present on the surface. Whether the cave floor had more ice and water than the previous year is open to conjecture. Nevertheless it is of interest that the flow-through model had $~ 85 \%$ of the ice mass remaining after one year of evolution.

The modeled interior cave air temperature and relative humidity were as expected in that the seasonal variation followed that of the exterior air data. The modeled interior air temperature was taken as the wetbulb temperature of the exterior air data and therefore was several degrees cooler at any given time than the exterior air. Similarly the interior relative humidity (RH) was taken as the RH corresponding to the wetbulb temperature and hence is somewhat higher than that of exterior air. Otherwise the variations of the interior cave air temperature and $\mathrm{RH}$ follow closely the variations of the exterior air.

It is evident, however, that the flow-through cave modeled air temperatures and RH (Fig. 5) do not agree well with the measurements as summarized in Fig. 3A. In fact, they appear to have as little obvious relation as Fig. 3A and 3B have to each other.

The static cave model results are shown in Fig. 6-7. The mass balance is summarized in Fig. 6, where it can be seen that the static cave model (as well as flow-through cave configurations with reduced wind speeds) are adept at preserving ice. The static model produced an excess ice mass of approximately $14 \%$ over the course of the year studied. Again, since no observations of the floor ice budget are available it is difficult to determine which model was more accurate in predicting the actual ice mass budget. Both models predict small amounts of ice gain or loss.

Figure 7A shows the results of the model where incoming cave air simply is transported (without modification) into the cave, where it is then permitted to equilibrate $\mathrm{RH}$ and temperature depending on the floor ice/water temperature and the temperature and thermal characteristics of the cave walls. As outlined above, the air is flushed out of the cave (and new exterior air settles into the cave) whenever the exterior air is colder than the interior air. As can be seen in Fig. 7A, the cave air is mostly undisturbed throughout the warm summer months. During late fall and early winter, however, cold exterior air settled into the cave when the cave air was warmer than the exterior air. The imported air was, for a time, somewhat dry (see RH variations). After enough time had elapsed, however, the cave air slug gradually became more humid and the new air slug equilibrates with the rest of the temperatures in the cave. 
Note, however, that the modeled interior cave air temperatures are somewhat higher than the measurements shown in Fig. 3A. As shown in Table 1 the mean annual interior air temperature was measured to be $-0.7^{\circ} \mathrm{C}$, whereas the modeled mean annual air temperature for the static cave configurations was $2.1^{\circ} \mathrm{C}$ (Table 2 row 1 ). While the RH mean values were similar between data and model (99.7\% data vs. 94.4\% static model), the range (maxmin) and standard deviations were quite different (1.1\% vs. $8.0 \%$ respectively). A visual comparison of Fig. $3 \mathrm{~A}$ and $7 \mathrm{~A}$ readily confirms the fact that the modeled RH exhibits greater extremes than the data.

Next, the current static cave model was modified to include a crucial element of the Flow-through model: the incoming air was chilled to the wetbulb temperature and the RH was set to the RH corresponding to the wet-bulb temperature. This modification was added in order to simulate the flow of the incoming air through wet rock rubble. The result of this "hybrid" model is shown in Fig. 7B. Chilling the

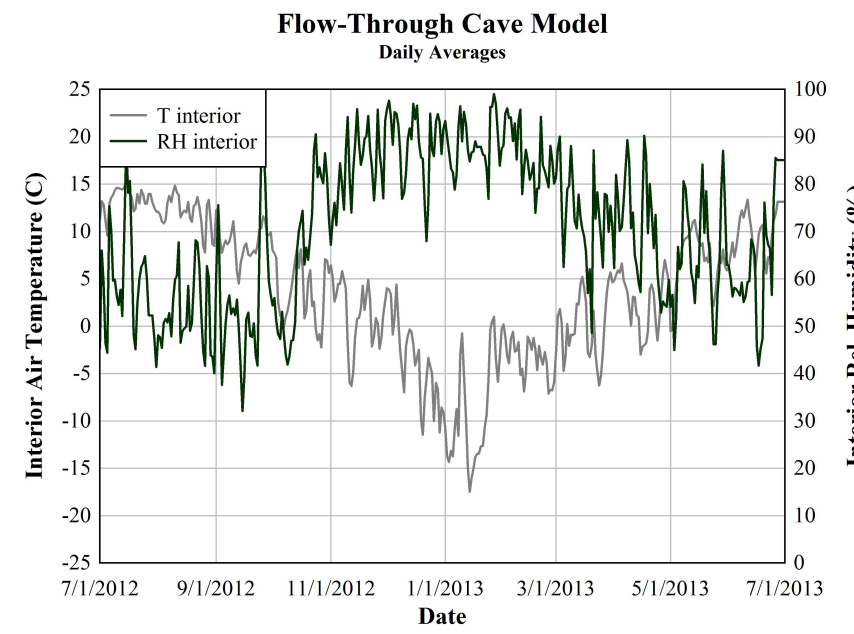

Fig. 5. Daily averages of the Flow-Through Cave Model results. In this model, the temperature and rel. humidity of the incoming air are taken as the external wet-bulb temperature and the rel. humidity at the external wet-bulb temperature.

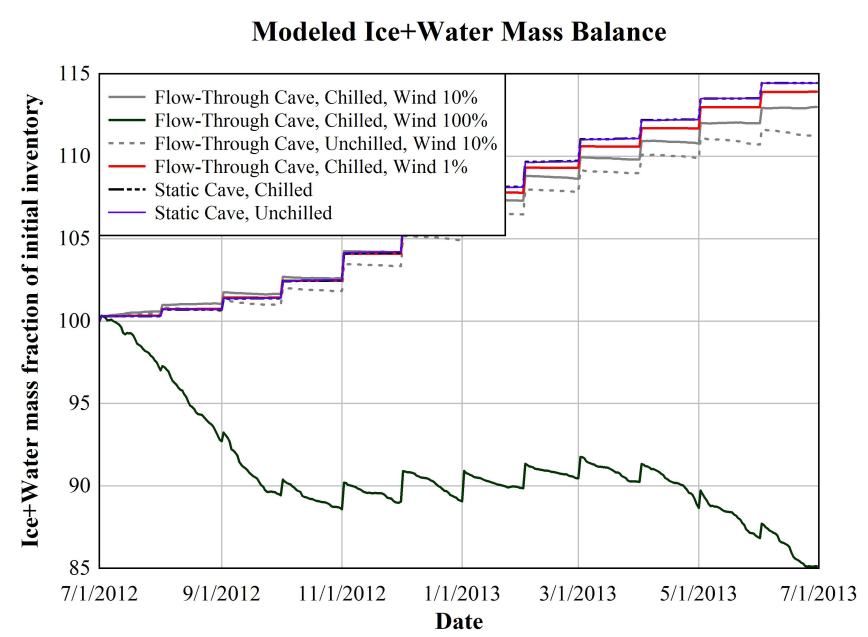

Fig. 6. Combined ice + water mass inventory for the year modeled. The Flow-through model with unscaled exterior wind had a slight loss of mass $(\sim 15 \%)$ over the course of a year. The other model configurations had a slight annual gain (10-14\%) of mass. In this figure "Chilled" refers to the air entering the cave has been chilled to the wet-bulb temperature of the exterior air. Both the flow-through and static cave models are capable of preserving ice year-round, and hence both models are viable ice cave models. incoming air results in a lower mean and median cave air temperature, as shown in Table 2 (rows 3-4). The mean annual air temperature was reduced by $\sim 3^{\circ} \mathrm{C}$ to a value of $-1.1^{\circ} \mathrm{C}$, and the min and max daily average temperature was $-13.0^{\circ} \mathrm{C}$ and $3.6^{\circ} \mathrm{C}$, respectively. Similarly the $\min$ of the daily average $\mathrm{RH}$ increased to $67.8 \%$, bringing both the temperature and $\mathrm{RH}$ closer to that measured (Table 1 rows $1-2)$.

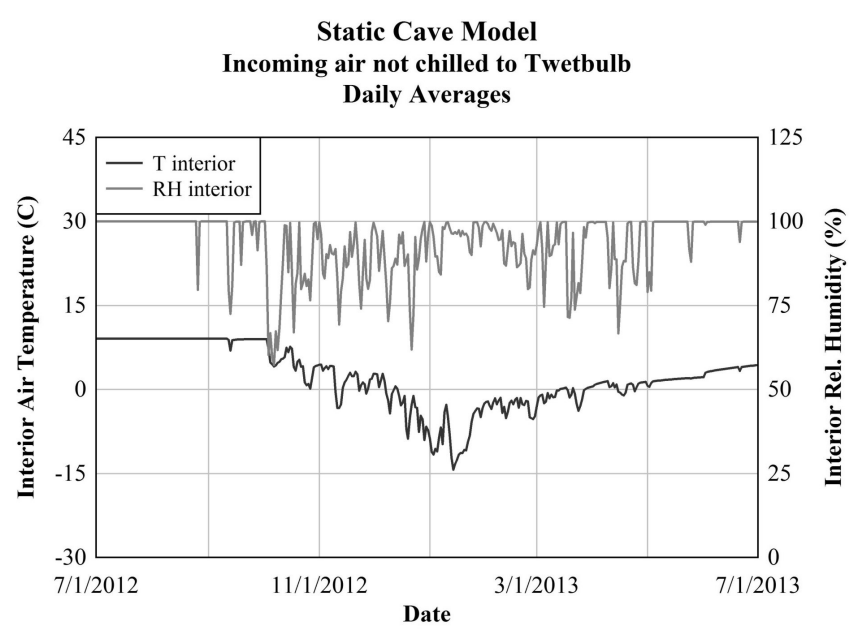

A.

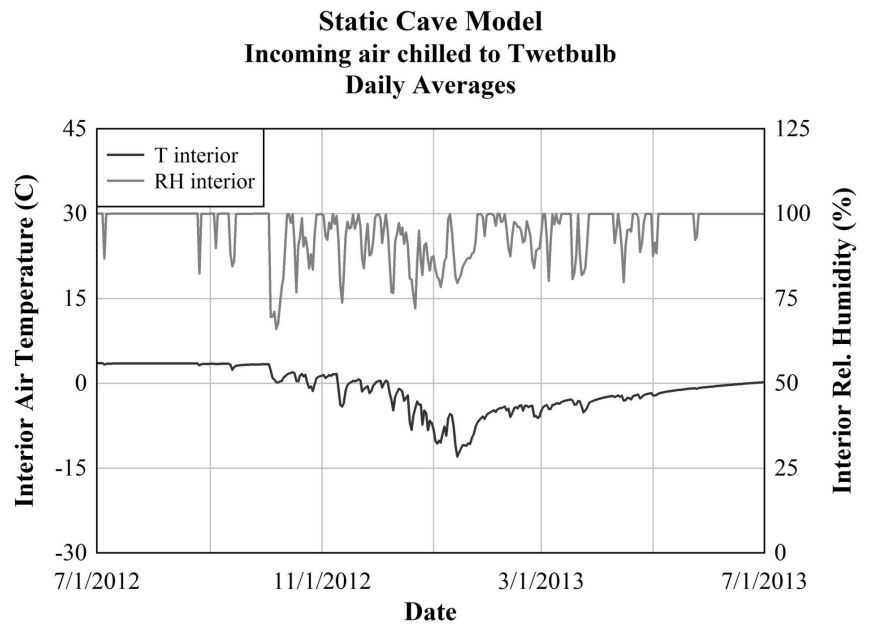

B.

Fig. 7. Static cave model configurations. In A. the static cave model used ambient incoming external air $\mathrm{T}$ and $\mathrm{RH}$. Once in the cave, the air slug was permitted to adjust to the temperature and $\mathrm{RH}$ as dictated by wall thermal properties. In B. the model chilled the incoming cave air $\mathrm{T}$ and $\mathrm{RH}$ to the wet-bulb points (simulating airflow through porous wet rock, with wet cave walls). Daily averages shown.

Table 2. Statistical properties of the model output. The rows are arranged according to the cave model: static refers to the "static cave model". The term "Static chilled" refers to the augmented static cave model where the incoming air was chilled to the wet-bulb $\mathrm{T}$ and $\mathrm{RH}$.

\begin{tabular}{|c|c|c|c|c|c|}
\cline { 2 - 6 } \multicolumn{1}{c|}{} & mean & median & min & max & $\begin{array}{c}\text { Std. } \\
\mathbf{d e v}\end{array}$ \\
\hline Static T & $2.1^{\circ} \mathrm{C}$ & $1.9^{\circ} \mathrm{C}$ & $-14.3^{\circ} \mathrm{C}$ & $9.1^{\circ} \mathrm{C}$ & $5.5^{\circ} \mathrm{C}$ \\
\hline Static RH & $94.4 \%$ & $99.6 \%$ & $61.9 \%$ & $\begin{array}{c}100.0 \\
\%\end{array}$ & $8.0 \%$ \\
\hline $\begin{array}{c}\text { Static } \\
\text { chilled T }\end{array}$ & -1.1 & -0.8 & -13.0 & 3.6 & 3.8 \\
\hline $\begin{array}{c}\text { Static } \\
\text { chilled RH }\end{array}$ & 95.2 & 99.9 & 67.8 & 100.0 & 7.1 \\
\hline $\begin{array}{c}\text { Flow- } \\
\text { through T }\end{array}$ & 3.6 & 4.4 & -17.5 & 15.6 & 7.4 \\
\hline $\begin{array}{c}\text { Flow- } \\
\text { through RH }\end{array}$ & 70.8 & 72.2 & 32.1 & 99.0 & 16.1 \\
\hline
\end{tabular}




\section{DISCUSSION AND CONCLUSION}

Our observations and models suggest that latent heat plays a significant role in the preservation of ice within Shoshone Ice Cave. Previous researchers have suggested that evaporative cooling effects may contribute to the formation of ice in caves (e.g., Browne, 1865), but the concept was not elucidated in sufficient detail in their work. Moreover, there is a need to quantify the relative contribution of evaporative cooling in numerical ice cave models.

The reported winds in the cave, as well as the presence of moist walls at the cave entrance, have motivated this study; a static cave should have winds only during certain times of the year. In addition, the presence of wet porous walls should chill the incoming air to the wet-bulb temperature.

Wigley \& Brown (1971) examined a related, but not identical phenomenon, to what we describe here. Wigley \& Brown (1971) modeled the longitudinal humidity and temperature profiles in caves (not necessarily ice caves). In their work, Wigley \& Brown modeled the flow of air through a shaft with moist walls. Heat and moisture were exchanged between the airflow and the wall. Applied to a cave, Wigley \& Brown (1971) deduced that the effect of latent heat then could create a cold zone near the cave entrance due to evaporation from the wall in winter and in transition periods when the incoming air was dry, but in summer could create a warming effect as the moist summer air condensed on the cooler cave walls. Condensation resulting from warm air flowing by cooler cave walls have been noted elsewhere (e.g., Tarhule-Lips $\&$ Ford, 1998). The cooling effect in the present study is also due to latent heat exchange but the physical setting is quite different from Wigley and Brown (1971). In this study the airflow reaches the wet-bulb temperature because it flows through the small pore spaces of a pile of wet rocks and equilibrium is assumed.

We have compared ice mass balance model predictions as well as cave interior air temperature and $\mathrm{RH}$ with observations. Since no ice budget observations were available to compare with the model output we have instead focused on the cave microclimate, in particular air temperature and relative humidity.

While both models predicted different amounts of ice mass gain/loss on the cave floor, we find it unlikely that the flow-through ice cave model applies to the Shoshone Ice Cave. Our findings instead suggest that a hybrid model consisting of a static ice cave model combined with chilling the incoming air to the wet-bulb temperature fits the observations best. There are some noteworthy differences between our hybrid model and the observations. One such difference involves the apparent greater variability in $\mathrm{RH}$ as modeled. A possible explanation for the natural cave exhibiting less variability in $\mathrm{RH}$ than the model is that the modeled latent heat (and associated mass transfer) Equations (5-7) somehow do not sufficiently account for the fluxes. Equations (5-7) are applicable to situations where laminar flow and free convection are applicable to mass transfer. It is possible that refinements to the model where turbulent mass transfer is taken into account would diminish these apparent differences. Nevertheless, the hybrid model agreement with the observations is sufficiently close to support our thesis that the Shoshone Ice Cave is essentially a static ice cave, but with latent heat playing a more prominent role than usual for static caves. It is perhaps not surprising that observations from the Shoshone Ice Cave are best explained by a combination of flow-through cave and static cave effects the wind has an important effect in the cave but it is not constant. Future studies could perhaps provide a more nuanced characterization of the airflow properties within lava tube caves in an effort to understand their internal climatic zones.

\section{ACKNOWLEDGEMENTS}

The authors would like to thank Fred Cheslik and the Shoshone Indian Ice Caves for permitting us to instrument the cave, and for their hospitality. We thank three anonymous reviewers who provided useful comments and improvements to the manuscript. We also thank NASA and the Idaho Space Grant Consortium for partial support.

\section{REFERENCES}

Badino G., 2010 - Underground meteorology - "What's the weather underground?" Acta Carsologica, 39: 427-448.

Balch E.S., 1900 - Glacières or Freezing Caverns. Allen, Lane \& Scott, $337 \mathrm{p}$.

Browne G.F., 1865 - Ice-Caves of France and Switzerland. Longmans, Green \& Co., 315 p.

Campbell G. S. \& Norman J. M., 1998 - An Introduction to Environmental Biophysics, $2^{\text {nd }}$ edition. Springer, 286 p. http://dx.doi.org/10.1007/978-1-4612-1626-1

Harrington E.R., 1934 - The origin of ice caves. The Journal of Geology, 42 (4): 433-436. http://dx.doi.org/10.1086/624181

Luetscher M., \& Jeannin P.-Y., 2004 - A process-based classification of alpine ice caves. Theoretical and Applied Karstology, 17: 61-66.

Luetscher M., Lismonde B. \& Jeannin P.-Y., 2008 Heat exchanges in the heterothermic zone of a karst system: Monlesi Cave, Swiss Jura Mountains. Journal of Geophysical Research, 113: F02025. http://dx.doi.org/10.1029/2007JF000892

Obleitner F. \& Spötl C., 2011 - The mass and energy balance of ice within the Eisriesenwelt Cave, Austria. The Cryosphere, 5: 245-257. http://dx.doi.org/10.5194/tc-5-245-2011

Ohata T., Furukawa T. \& Higuchi K., 1994 Glacioclimatological study of perennial ice in the Fuji Ice Cave, Japan. Part 1. seasonal variation and mechanism of maintenance. Arctic and Alpine Research, 26 (3): 227-237. http://dx.doi.org/10.2307/1551935

Paterson W.B., 1994 - The Physics of Glaciers, $3^{\text {rd }}$ edition, Butterworth \& Heinemann. 481p.

Perşoiu A., Onac B.P. \& Perşoiu I., 2011a - The interplay between air temperature and ice mass balance changes in Scărişoara Ice Cave, Romania. Acta Carsologica, 40 (3): 445-456.

Perşoiu A., Onac B.P., Wynn J.G., Bojar A.-V. \& Holmgren K., 2011b - Stable isotope behavior during cave ice formation by water freezing in Scărişoara Ice Cave, Romania. Journal of Geophysical Research, 116: D02111. http://dx.doi.org/10.1029/2010JD014477

Pflitsch A. \& Piasecki J., 2003 - Detection of an airflow system in Niedzwiedzia (Bear) Cave, Kletno, Poland. Journal of Cave and Karst Studies, 65 (3): 160-173. 
Robertson E.C. \& Peck D.L., 1974 - Thermal conductivity of vesicular basalt from Hawaii. Journal of Geophysical Research, 79 (32): 4875-4888.

http://dx.doi.org/10.1029/JB079i032p04875

Schöner W., Weyss G. \& Mursch-Radlgruber E., 2011 Linkage of cave-ice changes to weather patterns inside and outside the cave Eisriesenwelt (Tennengebirge, Austria). The Cryosphere, 5 (3): 603-616. http://dx.doi.org/10.5194/tc-5-603-2011

Silvestru E., 1998 - Perennial ice in caves in temperate climate and its significance. Theoretical and Applied Karstology, 11-12: 83-93.

Swartzlow C.R., 1935 - Ice caves in northern California. The Journal of Geology, 43 (4): 440-442. http://dx.doi.org/10.1086/624321

Tarhule-Lips R.A. \& Ford D.C., 1998 - Condensation corrosion in caves on Cayman Brac and Isla De Mona. Journal of Cave and Karst Studies, 60: 84-95.
Wigley T.M.L., 1967 - Non-steady flow through a porous medium and cave breathing. Journal of Geophysical Research, 72: 3199-3205.

http://dx.doi.org/10.1029/JZ072i012p03199

Wigley T.M.L., Brown C., 1971 - Geophysical applications of heat and mass transfer in turbulent pipe flow. Boundary-Layer Meteorology, 1: 300-320. http://dx.doi.org/10.1007/BF02186034

Wigley T.M.L., Brown M.C., 1976 - The physics of caves. In: Ford T.D., Cullingford C.H.D. (Eds.), The science of speleology. Academic Press, 329-344.

Williams K.E., Toon O.B., Heldmann J.L., McKay C., Mellon M.T., 2008 - Stability of mid-latitude snowpacks on Mars. Icarus, 196: 565-577.

Wisian K.W., Blackwell D.D., \& Richards M., 1999 - Heat flow in the western United States and extensional geothermal systems. Twenty-Fourth Workshop on Geothermal Reservoir Engineering. Stanford, CA: 219-226. 